\title{
Article \\ Examine the Association between Metabolic Syndrome and Frailty in an Older Asian Population
}

\author{
Hiep Huu Hoang Dao ${ }^{1}$, Anh Trung Nguyen ${ }^{2,3}{ }^{-}$, Huyen Thi Thanh $\mathrm{Vu}^{2,3}{ }^{(D)}$ and Tu Ngoc Nguyen $1, * \mathbb{C}$ \\ 1 Westmead Applied Research Centre, Faculty of Medicine and Health, The University of Sydney, \\ Sydney, NSW 2145, Australia; hdao5419@uni.sydney.edu.au \\ 2 Department of Geriatrics, Hanoi Medical University, Hanoi 100000, Vietnam; \\ trunganhvlk@gmail.com (A.T.N.); vuthanhhuyen11@hmu.edu.vn (H.T.T.V.) \\ 3 Department of Endocrinology and Rheumatology, National Geriatric Hospital, Hanoi 100000, Vietnam \\ * Correspondence: ngoc.tu.nguyen@sydney.edu.au
}

check for updates

Citation: Dao, H.H.H.; Nguyen, A.T.; Vu, H.T.T.; Nguyen, T.N. Examine the Association between Metabolic

Syndrome and Frailty in an Older Asian Population. Diabetology 2022, 3, 108-116. https://doi.org/10.3390/ diabetology3010009

Academic Editor: Yoshifumi Saisho

Received: 1 December 2021

Accepted: 4 February 2022

Published: 8 February 2022

Publisher's Note: MDPI stays neutral with regard to jurisdictional claims in published maps and institutional affiliations.

Copyright: (c) 2022 by the authors. Licensee MDPI, Basel, Switzerland. This article is an open access article distributed under the terms and conditions of the Creative Commons Attribution (CC BY) license (https:// creativecommons.org/licenses/by/ $4.0 /)$.

\begin{abstract}
Background: There has been evidence that metabolic syndrome (MetS) may increase the risk of frailty. However, there is limited evidence on this association in Asian populations. Aims: This study aims to identify the association between MetS and frailty in older people in Vietnam. Methods: This is a cross-sectional analysis of a dataset that was obtained from an observational study on frailty and sarcopenia in patients aged $\geq 60$ at a geriatric hospital in Vietnam. Frailty was defined by the frailty phenotype. The participants were defined as having MetS if they had $\geq 3$ out of 5 criteria from the definition of the National Cholesterol Education Program (NCEP) Adults Treatment Panel (ATP) III. Multiple logistic regression models were performed to estimate the risk of having frailty in patients with MetS. Results: Of the 669 participants (mean age 71, 60.2\% female), 62.3\% had MetS and $39.0 \%$ were frail. The prevalence of frailty was $42.2 \%$ in participants with MetS and $33.7 \%$ in participants without MetS $(p=0.029)$. On the logistic regression models, MetS was associated with an increased likelihood of being frail (adjusted OR 1.52, 95\%CI 1.01-2.28), allowing for age, sex, education, nutritional status, history of hospitalization, and chronic diseases. Conclusion: There was a significant association between MetS and frailty in this population. Further longitudinal studies are required to confirm this association.
\end{abstract}

Keywords: metabolic syndrome; diabetes; hypertension; obesity; frailty; older people; Asian

\section{Introduction}

In recent years, with ageing and considerable changes in population structure worldwide, ranging from higher-income regions to the lesser-developed nations, frailty has emerged as a public health interest due to its debilitating impacts on older people [1,2]. Frailty is characterized by a gradual depletion in physiological reserve and homeostatic tolerance following exposure to stressors [2]. A recent systematic review of studies across 62 countries showed that frailty was present in $12 \%$ to $24 \%$ in community-dwelling populations [1]. Such common geriatric conditions predispose older people to various adverse health outcomes, including falls, delirium, hospitalization, or even death, and thus is regarded as a crucial transition between healthy ageing and disability [2]. Even though frailty can be characterized by a plethora of frameworks that have been proposed by different organizations, Fried's phenotypic classification framework remains prominent owing to its practicality. In 2001, Fried et al. proposed a phenotypic frailty criteria for frailty, thus enabling the classification of older people based on their frailty status, taking into account five adverse health features: unexplained weight loss, exhaustion, reduced physical activity, low grip strength, and slow gait speed [3].

On the other hand, metabolic syndrome (MetS), or so-called Syndrome $\mathrm{X}$ is also a predominant disorder in the elderly [4]. MetS describes a constellation of metabolic disorders that are characterized by hypertriglyceridaemia, central adiposity, hypercholesterolaemia, 
insulin resistance, and hypertension [5]. According to the classification framework that was established by the National Cholesterol Education Program (Adult's Treatment Panel III), the definition of metabolic syndrome warrants the presence of $\geq 3$ of the aforementioned adverse features [6]. Understanding the relationship between MetS and frailty could justify the role of MetS management in frailty prevention for older people, as all of the five components of MetS are modifiable. Several studies have reported the association between frailty and metabolic syndrome. However, the majority of the relevant literature regarding this topic focuses on Caucasian populations and there is limited evidence on this topic in the context of other ethnic groups, in particular in Asian populations [7-15].

Therefore, this study aimed to explore this discrepancy, by investigating whether there is a significant correlation between MetS and frailty in older people in Vietnam-a country that is situated in the Southeast Asian region. Previous studies in Vietnam have shown that the prevalence of frailty was $21.7 \%$ in community-dwelling older people [16] and $32-55 \%$ in older hospitalized patients $[17,18]$. We hypothesized that in older people, MetS is associated with increased risk of acquiring frailty.

\section{Methods}

\subsection{Participants}

This study was a secondary analysis that was based on a primary study investigating the prevalence of sarcopenia in older patients in Vietnam. The details of this study were described in a previous publication [19]. Consecutive patients aged 60 years or above at a geriatric hospital in Vietnam were recruited from 1/2018 to 10/2018.

\subsection{Data Collection}

Data in the primary study were collected from patients' medical records and measurements. The information from medical records were extracted by the Vietnamese investigators using a pre-defined data collection form, including demographic characteristics and medical history. Comorbidities were obtained based on a pre-defined list. The nutritional status was evaluated using the Mini Nutritional Assessment Short Form (MNA-SF) tool (maximum score of 14 points, and a total score of $\leq 7$ points was indicative of a malnourished status [20]). The participants' weight (in kg) and height (in m) were measured following standard procedures. The body mass index (BMI) was calculated as weight $/$ height $^{2}\left(\mathrm{~kg} / \mathrm{m}^{2}\right)$ and the participants were categorized into three groups: underweight (BMI < 18.50), normal (BMI 18.50-24.99), and overweight (BMI $\geq 25.00$ ). The participants' handgrip strength was measured using a dynamometer (Jamar TM Hydraulic Hand Dynamometer 5030 J1, made in the USA) when participants were sitting with their elbows flexed at a 90-degree angle. The grip strength measurements were taken once on each hand and the highest value of the two readings was recorded and utilized for analysis.

Metabolic syndrome definition: Metabolic syndrome (MetS) was defined according to the revised framework by the National Cholesterol Education Program (NCEP) Adult Treatment Panel III [6]. The definition incorporates five major metabolic disturbances: abdominal obesity, hyperglycaemia, hypertriglyceridaemia, low high-density lipoprotein (HDL) cholesterol, and hypertension. The presence of at least three out of the five factors confers the acquisition of MetS.

(1) Abdominal obesity: defined as the waist circumference $\geq 102 \mathrm{~cm}$ in men, and $\geq 88 \mathrm{~cm}$ in women.

(2) Hyperglycaemia: fasting serum blood glucose (BGL) of $\geq 100 \mathrm{mg} / \mathrm{dL}$ or a concurrent history of diabetes.

(3) Hypertriglyceridaemia: defined as the serum triglyceride (TG) level of $\geq 150 \mathrm{mg} / \mathrm{dL}$.

(4) Low HDL cholesterol: defined as the serum HDL cholesterol level of $<40 \mathrm{mg} / \mathrm{dL}$ in men or $<50 \mathrm{mg} / \mathrm{dL}$ in women.

(5) Hypertension: defined as having a systolic blood pressure (SBP) of $\geq 130 \mathrm{mmHg}$ or a diastolic blood pressure (DBP) of $\geq 85 \mathrm{mmHg}$ or concurrent history of hypertension. 
All the measurements were obtained either through direct measurements by the research staff (waist circumference, blood pressure) or the blood test results (BGL, serum HDL, TG).

Frailty definition: Frailty was defined by the frailty phenotype (Fried's frailty criteria), which was composed of five components: shrinking, weakness, exhaustion, slowness, and low physical activity [3]. Patients were classified as being frail if they met 3 or more out of the 5 components (1-2: prefrail, 0 : robust). However, for the purpose of this study, frailty was treated as a binary variable, where presence of $\geq 3$ features served as a cut-off for the acquisition of frailty [3].

(1) Shrinking: defined as unintentional weight loss of $\geq 5 \%$ (or $4.5 \mathrm{~kg}$ ) in the last year or $\mathrm{BMI}<18.5$

(2) Weakness: cut-off points for low grip strength were $<28 \mathrm{~kg}$ in men and $<18 \mathrm{~kg}$ in women, as outlined by the Asian Working Group for Sarcopenia (AWGS) in 2019 [21].

(3) Self-reported exhaustion: In the primary study, the participants were asked to complete the Centre for Epidemiological Studies' Depression scale. Self-reported exhaustion was defined if a participant answered "occasionally or a moderate amount of time (3-4 days)", or "all of the time" (7 days) after being asked "whether you felt that everything you did was an effort" for the past week.

(4) Slowness based on walking speed: The gait speed was deemed "slow" if the participants were mobilized by $\leq 0.8 \mathrm{~m} / \mathrm{s}$ in the 4 -m walking test.

(5) Low physical activity: The International Physical Activity Questionnaire (IPAQ) was used to measure physical activity level of the participants [22]. Low physical activity was defined as a total score of $<600$ MET-minutes per week [22].

\subsection{Statistical Analysis}

Binary variables are presented as a frequency and percentage, and continuous variables are presented as the mean and standard deviation. Frailty was treated as a binary variable (yes/no) with the presence of $\geq 3$ adverse features confirming the frailty status. Comparisons between the participants with and without frailty were assessed using Chisquare tests for binary variables and Student's $t$-tests for continuous variables. Two-tailed $p$ values $<0.05$ were deemed statistically significant.

To examine the relationship between metabolic syndrome and frailty, univariate logistic regression was conducted, with frailty as the dependent variable and metabolic syndrome as the independent variable of interest. Univariate logistic regressions were also performed for other factors that can be associated with frailty, such as age, sex, education, living condition, and comorbidities. The relationship between metabolic syndrome and frailty was then examined further in multivariable logistic regression models, controlling for factors that had $p$-values $<0.05$ on the univariate logistic regressions. The results were presented as odds ratios (ORs) and 95\% confidence intervals (CIs). All the variables were checked for multicollinearity and interactions. Data analysis was conducted using SPSS for Windows 20.0 (IBM Corp., Armonk, NY, USA).

Sample size justification: The sample size of this study was estimated based on the Longitudinal Aging Study Amsterdam. Their baseline data showed that the prevalence of frailty in older participants with MetS was $16.7 \%$, and $8.8 \%$ in those without MetS. Therefore, we estimated that a sample size of at least 558 participants would enable the detection of a significant difference in frailty prevalence between older people with and without MetS (at $80 \%$ power, 5\% significance level)

\section{Results}

A total of 996 participants were recruited in the primary study. Among these, the data of frailty and metabolic syndrome were available for 669 participants $(n=669)$ whose characteristics were outlined in Table 1. Comparisons on baseline characteristics of participants with and without missing data of frailty and metabolic syndrome are presented in the Table S1. 
Table 1. Participant characteristics.

\begin{tabular}{|c|c|c|c|c|}
\hline & $\begin{array}{c}\text { All } \\
(\mathrm{N}=669)\end{array}$ & $\begin{array}{l}\text { Non-frail } \\
(\mathrm{N}=408)\end{array}$ & $\begin{array}{c}\text { Frail } \\
(N=261)\end{array}$ & $p$-Values \\
\hline Age (years) & $71.11 \pm 8.55$ & $68.88 \pm 7.40$ & $74.65 \pm 9.04$ & $<0.001$ \\
\hline Female & $403(60.2 \%)$ & $244(59.8 \%)$ & $159(60.9 \%)$ & 0.774 \\
\hline Body mass index $\left(\mathrm{kg} / \mathrm{m}^{2}\right)$ & $21.77 \pm 3.43$ & $22.49 \pm 2.86$ & $20.64 \pm 3.92$ & $<0.001$ \\
\hline Low education & $166(24.8 \%)$ & $67(16.4 \%)$ & $99(37.9 \%)$ & $<0.001$ \\
\hline Malnutrition (MNA $\leq 7$ ) & $57(8.5 \%)$ & $10(2.5 \%)$ & $47(18.0 \%)$ & $<0.001$ \\
\hline $\begin{array}{c}\text { Having history of hospitalization in } \\
\text { the past year }\end{array}$ & $304(45.4 \%)$ & $137(33.6 \%)$ & $167(64.0 \%)$ & $<0.001$ \\
\hline \multicolumn{5}{|c|}{ Chronic health conditions: } \\
\hline Hypertension & $318(47.5 \%)$ & $177(43.4 \%)$ & $141(54.0 \%)$ & 0.007 \\
\hline Diabetes & $133(19.9 \%)$ & $73(17.9 \%)$ & $60(23.0 \%)$ & 0.107 \\
\hline Myocardial infarction & $18(2.7 \%)$ & $9(2.2 \%)$ & $9(3.4 \%)$ & 0.333 \\
\hline Heart failure & $10(1.5 \%)$ & $3(0.7 \%)$ & $7(2.7 \%)$ & 0.043 \\
\hline Stroke & $25(3.7 \%)$ & $10(2.5 \%)$ & $15(5.7 \%)$ & 0.028 \\
\hline Peripheral vascular disease & $30(4.5 \%)$ & $16(3.9 \%)$ & $14(5.4 \%)$ & 0.379 \\
\hline Chronic kidney disease & $354(52.9 \%)$ & $179(43.9 \%)$ & $175(67.0 \%)$ & $<0.001$ \\
\hline $\begin{array}{c}\text { Chronic obstructive pulmonary } \\
\text { disease }\end{array}$ & $251(37.5 \%)$ & $143(35.0 \%)$ & $108(41.4 \%)$ & 0.099 \\
\hline Cancer & $10(1.5 \%)$ & $2(0.5 \%)$ & $8(3.1 \%)$ & 0.007 \\
\hline Dementia & $4(0.6 \%)$ & $0(0)$ & $4(1.5 \%)$ & 0.012 \\
\hline \multicolumn{5}{|c|}{ Variables related to metabolic syndrome: } \\
\hline $\begin{array}{l}\text { Fasting serum blood glucose level } \\
\qquad(\mathrm{mg} / \mathrm{dL})\end{array}$ & $136.8 \pm 438.4$ & $143.8 \pm 551.4$ & $125.8 \pm 130.9$ & 0.606 \\
\hline Serum triglyceride level (mg/dL) & $\begin{array}{c}265.0 \pm \\
1274.1\end{array}$ & $\begin{array}{c}299.3 \pm \\
1623.1\end{array}$ & $211.5 \pm 205.4$ & 0.385 \\
\hline $\begin{array}{l}\text { Serum HDL cholesterol level } \\
\text { (mg/dL) }\end{array}$ & $58.6 \pm 216.4$ & $55.4 \pm 195.9$ & $63.5 \pm 245.3$ & 0.638 \\
\hline $\begin{array}{l}\text { Systolic blood pressure level } \\
(\mathrm{mmHg})\end{array}$ & $125.2 \pm 13.5$ & $125.1 \pm 12.4$ & $125.3 \pm 15.1$ & 0.845 \\
\hline $\begin{array}{l}\text { Diastolic blood pressure level } \\
(\mathrm{mmHg})\end{array}$ & $77.0 \pm 8.2$ & $76.8 \pm 8.1$ & $77.2 \pm 8.4$ & 0.523 \\
\hline Waist circumference $(\mathrm{cm})$ & $84.3 \pm 33.3$ & $84.6 \pm 9.5$ & $83.9 \pm 52.1$ & 0.790 \\
\hline \multicolumn{5}{|c|}{ Variables related to frailty: } \\
\hline Grip strength (kg) & $17.2 \pm 7.8$ & $20.1 \pm 7.7$ & $12.7 \pm 5.5$ & $<0.001$ \\
\hline Gait speed (m/sec) & $0.6 \pm 0.3$ & $0.7 \pm 0.4$ & $0.5 \pm 0.2$ & $<0.001$ \\
\hline $\begin{array}{l}\text { Shrinking (weight loss of } \geq 5 \% \text { or } \\
4.5 \mathrm{~kg} \text { in the last year or } \mathrm{BMI}<18.5 \text { ) }\end{array}$ & $141(21.1 \%)$ & $29(7.1 \%)$ & $112(43.1 \%)$ & $<0.001$ \\
\hline Self-reported exhaustion & $97(14.5 \%)$ & $5(1.2 \%)$ & $92(35.2 \%)$ & $<0.001$ \\
\hline $\begin{array}{c}\text { Total IPAQ score (MET-minutes } \\
\text { per week) }\end{array}$ & $\begin{array}{c}1584.5 \pm \\
1847.6\end{array}$ & $\begin{array}{c}2169.3 \pm \\
1970.4\end{array}$ & $\begin{array}{c}645.1 \pm \\
1111.5\end{array}$ & $<0.001$ \\
\hline
\end{tabular}

Continuous data are presented as the mean \pm standard deviation. Categorical data are shown as $\mathrm{n}(\%)$. MNA, Mini Nutritional Assessment. SBP, systolic blood pressure. DBP, diastolic blood pressure. HDL, high-density lipoprotein. BMI, Body Mass Index. IPAQ: International Physical Activity Questionnaire.

The participants had a mean age of $71.1 \pm 8.5$. Among the 669 participants, $60.2 \%$ were females and $39.0 \%$ were classified as being frail. The most common chronic health conditions were chronic kidney disease (CKD, 52.9\%), followed by hypertension (47.5\%), chronic obstructive pulmonary disease (COPD, 37.5\%), and diabetes (19.9\%). Chronic health conditions were more prevalent in the frail population; however, such associations were only significant in hypertension, heart failure, stroke, CKD, cancer, and dementia $(p<0.05)$. Furthermore, the prevalence of low educational status $(37.9 \%$ in frail versus $16.4 \%$ in non-frail) and recent hospitalizations $(64.0 \%$ in frail versus $33.6 \%$ in non-frail) were around two-fold higher in the frail participants compared to their non-frail counterparts $(p<0.001)$. Frailty was also associated with a significantly higher rate of malnutrition at $18.0 \%$ (compared to $2.5 \%$ in the non-frail participants, $p<0.001$ ) within the study population. 
MetS was present in $62.3 \%$ of the participants. The prevalence of MetS was significantly higher in the frail participants $(67.4 \%$ compared to $59.1 \%$ in non-frail participants, $p=0.029)$. The prevalence of MetS and its constitutive components by frailty status is demonstrated in Table 2. Among the individual components of MetS, elevated blood pressure (67.3\%) was the most prevalent, followed by low HDL-C (66.8\%), high TG (63.2\%). elevated fasting plasma glucose $(61.3 \%)$, and central obesity $(25.0 \%)$.

Table 2. The prevalence of metabolic syndrome and its components by frailty status.

\begin{tabular}{|c|c|c|c|c|}
\hline & $\begin{array}{c}\text { All } \\
(\mathrm{N}=669)\end{array}$ & $\begin{array}{l}\text { Non-frail } \\
(N=408)\end{array}$ & $\begin{array}{c}\text { Frail } \\
(N=261)\end{array}$ & $p$-Values \\
\hline $\begin{array}{l}\text { Having metabolic syndrome } \\
\text { Abdominal obesity (waist }\end{array}$ & $417(62.3 \%)$ & $241(59.1 \%)$ & $176(67.4 \%)$ & 0.029 \\
\hline $\begin{array}{l}\text { circumference } \geq 102 \mathrm{~cm} \text { in men, } \\
\text { and } \geq 88 \mathrm{~cm} \text { in women) }\end{array}$ & $167(25.0 \%)$ & $104(25.5 \%)$ & $63(24.1 \%)$ & 0.693 \\
\hline $\begin{array}{l}\text { Fasting blood glucose } \geq 100 \mathrm{mg} / \mathrm{dL} \\
\text { or having a history of diabetes } \\
\text { SBP } \geq 130 \mathrm{mmHg} \text { or DBP }\end{array}$ & $410(61.3 \%)$ & $251(61.5 \%)$ & $159(60.9 \%)$ & 0.876 \\
\hline $\begin{array}{c}\geq 85 \mathrm{~mm} \bar{H} \text { or having a history of } \\
\text { hypertension }\end{array}$ & $450(67.3 \%)$ & $263(64.5 \%)$ & $187(71.6 \%)$ & 0.053 \\
\hline $\begin{array}{l}\text { HDL cholesterol }<40 \mathrm{mg} / \mathrm{dL} \text { in } \\
\text { men or }<50 \mathrm{mg} / \mathrm{dL} \text { in women. }\end{array}$ & $447(66.8 \%)$ & $264(64.7 \%)$ & $183(70.1 \%)$ & 0.147 \\
\hline Triglyceride $\geq 150 \mathrm{mg} / \mathrm{dL}$ & $423(63.2 \%)$ & $261(64.0 \%)$ & $162(62.1 \%)$ & 0.619 \\
\hline
\end{tabular}

Figure 1 presents the prevalence of frailty and its components in participants with and without MetS. Overall, the prevalence of frailty was higher in the participants with MetS than in the participants without MetS (42.2\% versus 33.7\%, respectively, $p=0.029)$. Among the five components of frailty, slowness was the most prevalent $(86.1 \%)$, followed by weakness $(71.3 \%)$ and low physical activity (29.9\%). The participants with MetS had a significantly higher prevalence of slowness, low physical activity, and exhaustion compared to those without MetS.

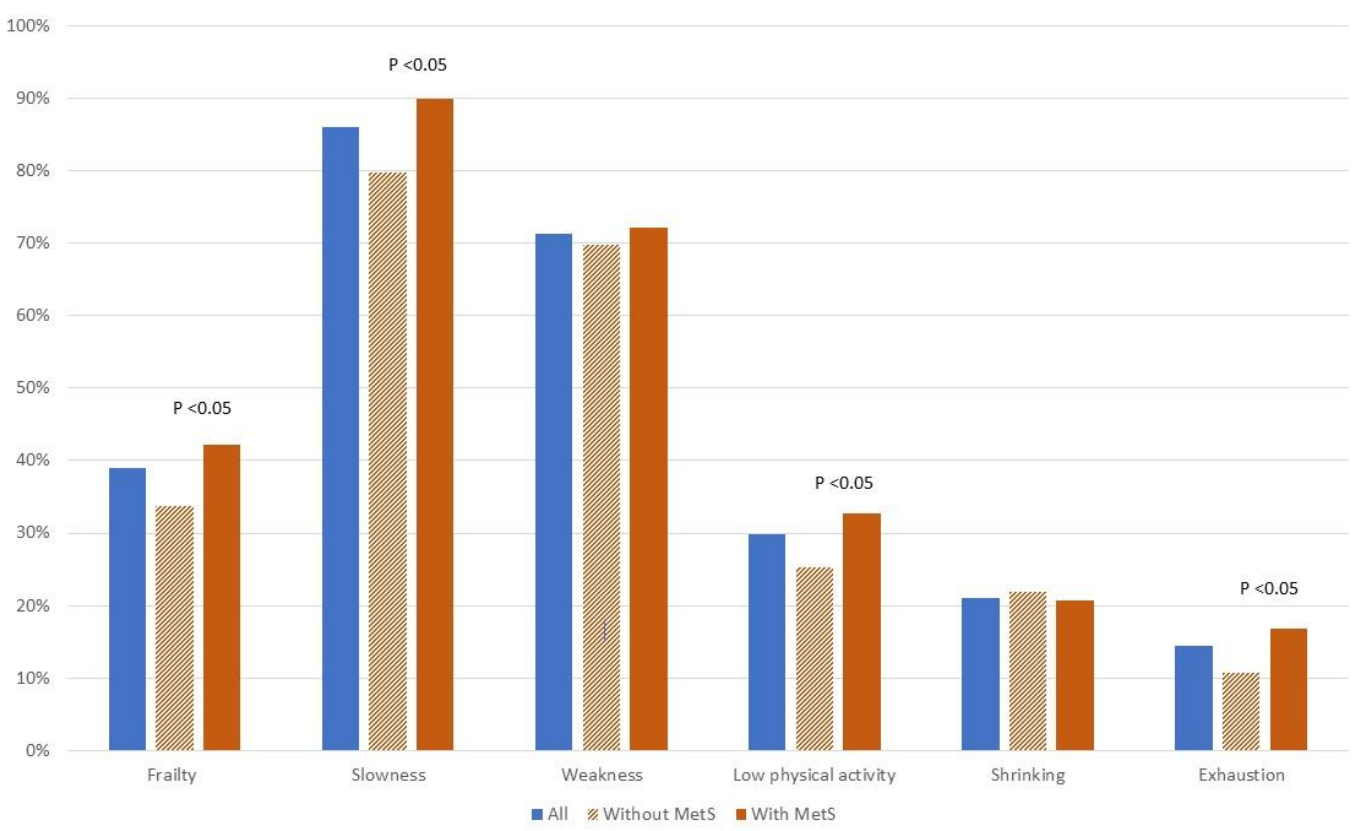

Figure 1. The prevalence of frailty and its components in participants with and without metabolic syndrome (MetS). 
On univariate logistic regression, there was a significant relationship between the presence of MetS and an increased risk of frailty (unadjusted OR 1.44, 95\%CI 1.04-1.99, $p=0.03$ ). This relationship was further explored in multivariate logistic regression that was adjusted to age, sex, and the variables that were found to demonstrate significant associations with frailty on univariate analyses (Table 3).

Table 3. Univariate logistic regression of the potentially associated factors of frailty.

\begin{tabular}{ccc} 
Variables & $\begin{array}{c}\text { Unadjusted Odds Ratios for } \\
\text { Being Frail (95\%CI) }\end{array}$ & $p$-Values \\
Having metabolic syndrome & $1.44(1.04-1.99)$ & 0.030 \\
Age (per year) & $1.10(1.08-1.12)$ & $<0.001$ \\
Female & $1.10(0.84-1.45)$ & 0.499 \\
Recruitment source (inpatients vs. outpatients) & $2.92(2.13-3.99)$ & $<0.001$ \\
Low education & $2.92(2.15-3.97)$ & $<0.001$ \\
Malnutrition & $9.14(4.71-17.74)$ & $<0.001$ \\
History of hospitalization in the last year & $2.99(2.26-3.95)$ & 0.001 \\
Myocardial infarction & $0.88(0.38-2.01)$ & 0.760 \\
Heart failure & $1.95(0.80-4.75)$ & 0.143 \\
Stroke & $2.07(1.02-4.22)$ & 0.045 \\
Peripheral vascular disease & $1.07(0.59-1.94)$ & 0.830 \\
Chronic kidney disease & $2.66(1.98-3.58)$ & $<0.001$ \\
Chronic lung disease & $1.05(0.79-1.38)$ & 0.761 \\
Cancer & $4.26(1.12-16.15)$ & 0.033 \\
Dementia & $3.16(0.58-17.35)$ & 0.185 \\
\hline
\end{tabular}

After adjusting to age, sex, low educational, and nutritional statuses, recent hospitalization, recruitment resources, and chronic health conditions (CKD, stroke, and cancer), MetS still remained significantly associated with a higher risk frailty (Model 5, adjusted OR $1.54,95 \%$ CI 1.03-2.31, $p=0.036$ ) (Table 4).

Table 4. Multivariate logistic regression of metabolic syndrome on frailty status.

\begin{tabular}{ccc}
\hline & Adjusted Odds Ratios for Being Frail (95\%CI) & $p$ \\
\hline Model 1 & $1.42(1.00-2.00)$ & 0.049 \\
Model 2 & $1.42(1.00-2.02)$ & 0.049 \\
Model 3 & $1.47(1.01-2.14)$ & 0.045 \\
Model 4 & $1.62(1.10-2.38)$ & 0.015 \\
Model 5 & $1.54(1.03-2.31)$ & 0.036
\end{tabular}

Model 1: adjusted to age; Model 2: adjusted to age and education; Model 3: adjusted to age, education, nutritional status, and hospitalization in the past year; Model 4: adjusted to age, education, nutritional status, hospitalization in the past year, and chronic health conditions (chronic kidney disease, stroke, and peripheral vascular disease, cancer); Model 5: adjusted to age, sex, education, nutritional status, hospitalization in the past year, chronic health conditions (chronic kidney disease, stroke, and cancer), and recruitment sources

\section{Discussion}

In this study of 669 older participants, there was a high prevalence of frailty $(39.0 \%)$ and MetS $(62.3 \%)$. The presence of MetS was associated with a significantly higher likelihood of frailty in the participants.

Our findings on the significant association between MetS and frailty coincided with findings from several previous studies. Our literature search revealed that most of the studies on this topic that were conducted in Caucasian older populations [7-13], with only two studies reporting the association between frailty and metabolic syndrome in Asian populations [14,15]. Chao et al. found that among 2862 community-dwelling older adults, the presence of MetS was associated with a significantly higher risk of combined frailty/prefrailty (OR 2.53, 95\%CI 1.78-3.60) [14]. Lee et al. also reported that metabolic syndrome was strongly associated with frailty status (OR 3.2, 95\%CI 1.7-6.0) [15]. In a crosssectional study of 118 non-institutionalized older people in Italy (mean age $76.1 \pm 5.0$ years, 
$60 \%$ women), Viscogliosi et al. found that the prevalence of frailty was significantly higher in the participants with MetS compared to those without MetS (60.7\% vs. $12.9 \%$, respectively), and the adjusted odds ratio of MetS for frailty acquisition was comparable to our study at $1.53(95 \%$ CI 1.33-1.76) [7]. Their longitudinal data also showed that baseline MetS increased the risk of reduced handgrip strength and gait speed [23]. An analysis from the Salus in Apulia study in Italy also showed that metabolic syndrome was associated with an increased risk of physical frailty (OR 1.42, 95\%CI 1.00-2.03) [13]. In another cross-sectional study that was conducted in Germany, involving 1486 elderly participants with a mean age of 68.7 years, the odds of being prefrail/frail was significantly increased with the presence of MetS (adjusted OR 1.5, 95\%CI 1.2-1.9) [10]. Another study from 1247 elderly participants partaking in the Longitudinal Aging Study Amsterdam also reported a significantly higher prevalence of frailty in those with MetS (16.7\%) compared to their unaffected counterparts $(8.8 \%)$ [8]. In a longitudinal study by Perez-Tasigchana in Spain, after following 1499 community-dwelling participants (aged $\geq 60$ years) for 3.5 years, the authors found that the participants with MetS had higher risk of developing frailty than those without MetS (OR 1.85, 95\%CI 1.12-3.05), adjusting for the participants' socio-economic factors, healthy behaviours, and comorbidities [9].

Although the pathophysiological linkage between MetS and frailty is still an area of active research, several studies have suggested low-grade chronic inflammation state, high circulating inflammatory markers, and neuroendocrine dysfunction as common grounds between the two syndromes. A meta-analysis of 32 cross-sectional studies demonstrated significant associations between increased inflammatory markers, in particular IL-6 and C-reactive protein (CRP), with impaired muscle function, predisposing older people to increased risk of frailty [24]. Similarly, a pro-inflammatory state that was induced by adipokines and other inflammatory mediators was also postulated to be central to insulin resistance and thus MetS pathogenesis [25]. The individual components defining MetS were shown to contribute to the presence of frailty in several studies. Hypertension, in particular high systolic blood pressure, was shown to have a positive correlation with frailty in studies by Newman, Bastos-Barbosa et al. [26,27]. Abdominal obesity, after being adjusted for BMI, was demonstrated to increase the risk of frailty, on both the frailty index (FI) and the phenotypic classifications according to Hubbard et al. [28]. Several other studies showed that insulin resistance was amongst the most commonly-documented component of MetS, with respect to its association with frailty $[9,29]$. A longer duration of insulin resistance or overt diabetes, coupled with poor glycemic control could have resulted in suboptimal muscle quality and strength, thus directly increasing the odds of falls and frailty [30].

To the best of our knowledge, this study is the first of its kind to provide evidence on the association between metabolic syndrome and frailty in Vietnam. However, this study has several limitations. First, this was a secondary analysis, and thus, we were limited by the available data. A total of 327 participants, despite meeting criteria for inclusion from the primary study, was excluded from our analysis because of insufficient data to define frailty and MetS. Second, this study was conducted at only one geriatric hospital in Vietnam. This may explain why the prevalence of frailty and MetS in our studied population was higher than what has been reported in other studies with more general populations. Therefore, the studied population may not be representative for all older patients in Vietnam and the results should be interpreted cautiously. Although the ability for generalization was somewhat limited, owing to its single site nature, our study still remains relevant in a public health point-of-view, serving as a starting point for future studies linking the two prominent risk factors for adverse health outcomes in older people. As metabolic syndrome and its constitutive components are targetable pharmacologically and conservatively through public health directives, a significant relationship between MetS and frailty could aid decision-makers and justify the role of MetS management as a primary prevention for frailty syndrome in older people. 


\section{Conclusions}

This study found that metabolic syndrome was present in around two-thirds of the participants and was associated with increased risk of frailty. Further longitudinal studies are required to confirm this association. These findings support the routine assessment for frailty in older people with cardio-metabolic disorders.

Supplementary Materials: The following are available online at https:/ / www.mdpi.com/article/10 .3390 / diabetology3010009/s1, Table S1: Comparison between participants included and excluded from this study.

Author Contributions: All authors (H.H.H.D., T.N.N., H.T.T.V. and A.T.N.) contributed to the study conception and design. Participant recruitment and data curation were performed by H.T.T.V. and A.T.N. Data analysis were performed by H.H.H.D. and T.N.N. H.H.H.D. and T.N.N. wrote various drafts of the manuscript. T.N.N. is H.H.H.D.'s supervisor. All authors contributed to interpretation of data and commented on previous versions of the manuscript. All authors read and approved the final manuscript.

Funding: This research received no external funding.

Institutional Review Board Statement: The study was conducted according to the guidelines of the Declaration of Helsinki and approved by the Ethics Committee of the National Geriatric Hospital in Hanoi, Vietnam (protocol code 1235/IRB, date of approval 28/11/2017).

Informed Consent Statement: Informed consent was obtained from all subjects involved in the study.

Data Availability Statement: The study data is available from the corresponding author upon reasonable request.

Acknowledgments: We thank all participants for their participation in the study.

Conflicts of Interest: The authors declare no conflict of interest.

\section{References}

1. O'Caoimh, R.; Sezgin, D.; O’Donovan, M.R.; Molloy, D.W.; Clegg, A.; Rockwood, K.; Liew, A. Prevalence of frailty in 62 countries across the world: A systematic review and meta-analysis of population-level studies. Age Ageing 2021, 50, 96-104. [CrossRef] [PubMed]

2. Clegg, A.; Young, J.; Iliffe, S.; Rikkert, M.O.; Rockwood, K. Frailty in elderly people. Lancet 2013, 381, 752-762. [CrossRef]

3. Fried, L.P.; Tangen, C.M.; Walston, J.; Newman, A.B.; Hirsch, C.; Gottdiener, J.; Seeman, T.; Tracy, R.; Kop, W.J.; Burke, G.; et al. Frailty in older adults: Evidence for a phenotype. J. Gerontol. A Biol. Sci. Med. Sci. 2001, 56, M146-M156. [CrossRef] [PubMed]

4. Pucci, G.; Alcidi, R.; Tap, L.; Battista, F.; Mattace-Raso, F.; Schillaci, G. Sex- and gender-related prevalence, cardiovascular risk and therapeutic approach in metabolic syndrome: A review of the literature. Pharmacol. Res. 2017, 120, 34-42. [CrossRef]

5. Eckel, R.H.; Grundy, S.M.; Zimmet, P.Z. The metabolic syndrome. Lancet 2005, 365, 1415-1428. [CrossRef]

6. Expert Panel on Detection, Evaluation. Adults ToHBCi. Executive Summary of the Third Report of the National Cholesterol Education Program (NCEP) Expert Panel on Detection, Evaluation, and Treatment of High Blood Cholesterol in Adults (Adult Treatment Panel III). JAMA 2001, 285, 2486-2497. [CrossRef]

7. Viscogliosi, G. The Metabolic Syndrome: A Risk Factor for the Frailty Syndrome? J. Am. Med. Dir. Assoc. 2016, 17, 364-366. [CrossRef]

8. Hoogendijk, E.O.; Huisman, M.; van Ballegooijen, A.J. The role of frailty in explaining the association between the metabolic syndrome and mortality in older adults. Exp. Gerontol. 2017, 91, 5-8. [CrossRef]

9. Pérez-Tasigchana, R.F.; León-Muñoz, L.M.; Lopez-Garcia, E.; Gutierrez-Fisac, J.L.; Laclaustra, M.; Rodríguez-Artalejo, F.; GuallarCastillón, P. Metabolic syndrome and insulin resistance are associated with frailty in older adults: A prospective cohort study. Age Ageing 2017, 46, 807-812. [CrossRef]

10. Buchmann, N.; Spira, D.; Konig, M.; Demuth, I.; Steinhagen-Thiessen, E. Frailty and the Metabolic Syndrome-Results of the Berlin Aging Study II (BASE-II). J. Frailty Aging 2019, 8, 169-175. [CrossRef]

11. Kane, A.E.; Gregson, E.; Theou, O.; Rockwood, K.; Howlett, S.E. The association between frailty, the metabolic syndrome, and mortality over the lifespan. Geroscience 2017, 39, 221-229. [CrossRef] [PubMed]

12. Veronese, N.; Sigeirsdottir, K.; Eiriksdottir, G.; Marques, E.A.; Chalhoub, D.; Phillips, C.L.; Launer, L.J.; Maggi, S.; Gudnason, V.; Harris, T.B. Frailty and Risk of Cardiovascular Diseases in Older Persons: The Age, Gene/Environment Susceptibility-Reykjavik Study. Rejuvenation Res. 2017, 20, 517-524. [CrossRef] 
13. Castellana, F.; Lampignano, L.; Bortone, I.; Zupo, R.; Lozupone, M.; Griseta, C.; Daniele, A.; De Pergola, G.; Giannelli, G.; Sardone, R.; et al. Physical Frailty, Multimorbidity, and All-Cause Mortality in an Older Population From Southern Italy: Results from the Salus in Apulia Study. J. Am. Med. Dir. Assoc. 2021, 22, 598-605. [CrossRef]

14. Chao, C.T.; Lee, Y.H.; Li, C.M.; Han, D.S.; Huang, J.W.; Huang, K.C. Advanced Age and Chronic Kidney Disease Modify the Association Between Metabolic Syndrome and Frailty Among Community-Dwelling Elderly. Rejuvenation Res. 2020, $23,333-340$. [CrossRef]

15. Lee, W.J.; Peng, L.N.; Chen, L.K. Metabolic Syndrome and Its Components Are Associated with Frailty: A Nationwide PopulationBased Study in Taiwan. Aging Med. Healthc. 2020, 11, 47-52. [CrossRef]

16. Nguyen, A.T.; Nguyen, L.H.; Nguyen, T.X.; Nguyen, H.T.T.; Nguyen, T.N.; Pham, H.Q.; Tran, B.X.; Latkin, C.A.; Ho, C.S.H.; Ho, R.C.M.; et al. Frailty Prevalence and Association with Health-Related Quality of Life Impairment among Rural CommunityDwelling Older Adults in Vietnam. Int. J. Environ. Res. Public Health 2019, 16, 3869. [CrossRef]

17. Nguyen, A.T.; Nguyen, T.X.; Nguyen, T.N.; Nguyen, T.H.T.; Pham, T.; Cumming, R.; Hilmer, S.N.; Vu, H.T.T. The impact of frailty on prolonged hospitalization and mortality in elderly inpatients in Vietnam: A comparison between the frailty phenotype and the Reported Edmonton Frail Scale. Clin. Interv. Aging 2019, 14, 381-388. [CrossRef] [PubMed]

18. Nguyen, T.V.; Ly, T.T.; Nguyen, T.N. A Pilot Study of the Clinical Frailty Scale to Predict Frailty Transition and Readmission in Older Patients in Vietnam. Int. J. Environ. Res. Public Health 2020, 17, 1582. [CrossRef] [PubMed]

19. Nguyen, T.N.; Nguyen, T.N.; Nguyen, A.T.; Nguyen, T.X.; Nguyen, H.T.T.; Nguyen, T.T.H.; Pham, T.; Vu, H.T.T. Prevalence of sarcopenia and its associated factors in patients attending geriatric clinics in Vietnam: A cross-sectional study. BMJ Open 2020, 10, e037630. [CrossRef] [PubMed]

20. Kaiser, M.J.; Bauer, J.M.; Ramsch, C.; Uter, W.; Guigoz, Y.; Cederholm, T.; Thomas, D.R.; Anthony, P.; Charlton, K.E.; Maggio, M.; et al. Validation of the Mini Nutritional Assessment short-form (MNA-SF): A practical tool for identification of nutritional status. J. Nutr. Health Aging 2009, 13, 782-788. [CrossRef]

21. Chen, L.K.; Woo, J.; Assantachai, P.; Auyeung, T.W.; Chou, M.Y.; Iijima, K.; Jang, H.C.; Kang, L.; Kim, M.; Kim, S.; et al. Asian Working Group for Sarcopenia: 2019 Consensus Update on Sarcopenia Diagnosis and Treatment. J. Am. Med. Dir. Assoc. 2020, 21, 300-307.e2. [CrossRef]

22. Tran, D.V.; Lee, A.H.; Au, T.B.; Nguyen, C.T.; Hoang, D.V. Reliability and validity of the International Physical Activity Questionnaire-Short Form for older adults in Vietnam. Health Promot. J. Austr. 2013, 24, 126-131. [CrossRef]

23. Viscogliosi, G.; Andreozzi, P.; Ettorre, E.; Chiriac, I.M. The Metabolic Syndrome and the Phenotype of Frailty: A Causal Link? J. Am. Med. Dir. Assoc. 2016, 17, 956-957. [CrossRef]

24. Soysal, P.; Stubbs, B.; Lucato, P.; Luchini, C.; Solmi, M.; Peluso, R.; Sergi, G.; Isik, A.T.; Manzato, E.; Maggi, S.; et al. Inflammation and frailty in the elderly: A systematic review and meta-analysis. Ageing Res. Rev. 2016, 31, 1-8. [CrossRef] [PubMed]

25. Welty, F.K.; Alfaddagh, A.; Elajami, T.K. Targeting inflammation in metabolic syndrome. Transl. Res. 2016, 167, 257-280. [CrossRef] [PubMed]

26. Newman, A.B.; Gottdiener, J.S.; McBurnie, M.A.; Hirsch, C.H.; Kop, W.J.; Tracy, R.; Walston, J.D.; Fried, L.P. Associations of subclinical cardiovascular disease with frailty. J. Gerontol. A Biol. Sci. Med. Sci. 2001, 56, M158-M166. [CrossRef] [PubMed]

27. Bastos-Barbosa, R.G.; Ferriolli, E.; Coelho, E.B.; Moriguti, J.C.; Nobre, F.; Lima, N.K. Association of frailty syndrome in the elderly with higher blood pressure and other cardiovascular risk factors. Am. J. Hypertens 2012, 25, 1156-1161. [CrossRef]

28. Hubbard, R.E.; Lang, I.A.; Llewellyn, D.J.; Rockwood, K. Frailty, Body Mass Index, and Abdominal Obesity in Older People. J. Gerontol. Ser. A 2009, 65A, 377-381. [CrossRef]

29. Barzilay, J.I.; Blaum, C.; Moore, T.; Xue, Q.L.; Hirsch, C.H.; Walston, J.D.; Fried, L.P. Insulin resistance and inflammation as precursors of frailty: The Cardiovascular Health Study. Arch. Intern. Med. 2007, 167, 635-641. [CrossRef]

30. Park, S.W.; Goodpaster, B.H.; Strotmeyer, E.S.; de Rekeneire, N.; Harris, T.B.; Schwartz, A.V.; Tylavsky, F.A.; Newman, A.B. Decreased muscle strength and quality in older adults with type 2 diabetes: The health, aging, and body composition study. Diabetes 2006, 55, 1813-1818. [CrossRef] 